\title{
O mundo em partidas dobradas (leitura de "Elegia", de Carlos Drummond de Andrade)
}

\author{
Emílio Maciel | UFOP
}

Resumo: Leitura de "Elegia", de Carlos Drummond de Andrade, este ensaio detém-se sobre as implicaçôes retóricas e politicas da forma do poema, tomando como ponto de partida as tensóes entre a poesia e a crise da experiência no mundo moderno.

Palavras-chave: forma, experiência, retórica.

Elegia

Ganhei (perdi) meu dia.

E baixa a coisa fria

também chamada noite, e o frio ao frio

em bruma se entrelaça, num suspiro.

E me pergunto e me respiro

na fuga deste dia que era mil

para mim que esperava

os grandes sóis violentos, me sentia

tão rico deste dia

e lá se foi secreto, ao serro frio. 
Perdi minha alma à flor do dia ou já perdera

bem antes sua vaga pedraria?

Mas quando me perdi, se estou perdido

antes de haver nascido

e me nasci votado à perda

de frutos que não tenho nem colhia?

Gastei meu dia. Nele me perdi.

De tantas perdas uma clara via

por certo se abriria

de mim a mim, estela fria.

As árvores lá fora se meditam.

O inverno é quente em mim, que o estou berçando

e em mim vai derretendo

este torrão de sal que está chorando.

Ah, chega de lamento e versos ditos

ao ouvido de alguém sem rosto e sem justiça,

ao ouvido do muro,

ao liso ouvido gotejante

de uma piscina que não sabe o tempo, e fia

seu tapete de água, distraída.

E vou me recolher

ao cofre de fantasmas, que a notícia de perdidos

lá não chegue nem açule

os olhos policiais do amor-vigia.

Não me procurem que me perdi eu mesmo

como os homens se matam e as enguias

à loca se recolhem, na água fria.

Dia,

espelho de projeto não vivido,

e contudo viver era tão flamas

na promessa dos deuses; e é tão ríspido

em meio aos oratórios já vazios

em que a alma barroca tenta confortar-se

mas só vislumbra o frio noutro frio. 
Meu Deus, essência estranha ao vaso que me sinto, ou forma vã, pois que, eu essência, não habito vossa arquitetura imerecida; meu Deus e meu conflito, nem vos dou conta de mim, nem desafio as garras inefáveis: eis que assisto a meu desmonte palmo a palmo, e não me aflijo de me tornar planície em que já pisam servos e bois e militares em serviço da sombra, e uma criança que o tempo novo me anuncia e nega.

Terra a que me inclino sobre o frio da testa que se alonga, e sinto mais presente quanto aspiro em ti o fumo antigo dos parentes, minha terra, me tens; e teu cativo passeias brandamente como ao que vai morrer se estende a vista de espaços luminosos, intocáveis: em mim o que resiste são teus poros. E sou meu próprio frio que me fecho. Corto o frio da folha. Sou teu frio.

E sou meu próprio frio que me fecho longe do amor desabitado e líquido, amor em que me amaram, me feriram sete vezes por dia, em sete dias de sete vidas de ouro, amor, fonte de eterno frio, minha pena deserta, ao fim de março, amor, que contaria?

E já não sei se é jogo, ou se poesia.

Um dos poemas mais difíceis e discutidos de Fazendeiro do ar (1954), "Elegia", de Carlos Drummond de Andrade, inscreve-se num dos grandes filões da obra do poeta, ao colocar no centro da cena uma consciência às voltas com o inventário de suas perdas. Veio que já se insinuava com menos evidência desde o 
livro de estréia, é possível que sua principal virtude e novidade - decisiva para marcar a originalidade da assinatura de Drummond no modernismo brasileiro seja a extrema flexibilidade de estrutura formal que lhe corresponde, ao materializar o mergulho reflexivo do sujeito na metáfora de uma folha de partidas dobradas no qual fragmentos são dispostos, pesados e confrontados. De um lado, ao operar como um eixo centrípeto face ao tumulto de eventos, essa estrutura se mostrava um suporte perfeito para a dissonância constitutiva da experiência moderna, em peças onde, combinando proximidade e distância, catacreses tiradas de um livro contábil são como um pivô acomodando em torno de si a textura incomensurável das coisas. De outro, na medida em que dobrava essa mesma desordem ao filtro da observação a frio, tendo como apoio o tratamento da existência nos termos de uma desabusada pesagem de prós e contras, o dispositivo acrescentava ao coloquialismo pós-22 uma largueza temporal inédita, que corria de par com uma incansável escavação da superfície dos fatos. Naquela que pode ser identificada como a fase mais significativa de Drummond, tendo como pontos de inflexão a poesia participante de A rosa do povo (1945) e a reapropriação do legado clássico consolidada em Claro enigma (1951), trata-se um motivo capaz de criar elos de continuidade entre peças de feição bem diversa, sendo por isso mesmo ponto de partida privilegiado para discutir o sentido da transição que tem lugar entre os referidos volumes. Problema recentemente abordado com muita elegância por Vagner Camilo, num texto que procura ler a virada classicizante como cifra de luto político, a dificuldade associada a tal transição - vista como um movimento regressivo por críticos como Haroldo de Campos e Luiz Costa Lima -, encontra sem dúvida um eco muito evidente no poema que se toma agora por objeto de análise, e que constitui, como se verá, um dos momentos mais emblemáticos desse Drummond da madureza.

Composto de 10 estrofes irregulares e polimétricas, uma primeira vista de olhos sobre os versos mostra um todo a milhas de distância da feição angulosa de títulos como "O poema de sete faces" e "Contemplação no banco", com os quais "Elegia" no entanto poderia ser confrontado em termos temáticos. De saída, sua extrema dificuldade e densidade já podem ser percebidas com nitidez nas 4 linhas que compõem sua primeira estrofe - de certa forma, quase uma súmula do movimento em negaceio de todo o restante: começando com um hexassílabo encerrado num golpe seco, o acento peremptório do ponto final é aí

1. CAMILO. Drummond: da rosa do povo à rosa das trevas. 
contrabalançado pela leve síncope fornecida pelo verbo entre parênteses, cujo efeito parece ser transformar num jogo de soma zero a tensão entre o impacto da frase isolada e a bifurcação aberta pela equiparação-nivelamento de duas noções antônimas. No verso seguinte, contudo - quando ocorre a primeira de uma série de rimas que dará apoio ao poema -, a agilidade com que o eco sonoro chama atenção sobre si, depois de um impulso dado por um "E" paratático tensionando dois eventos modulados em tempos e durações distintos, pode até dar a impressão de atenuar com êxito o forte desajuste de velocidades. Ao mesmo tempo, empresta também unidade à ondulação que, se pressupõe de início o mínimo de distância necessária para narrar um passado perfeito - reforçando assim a idéia de um gesto instantâneo e, ao que tudo indica, concluído - depois cede espaço a um evento o "baixar da noite" - que, além de ser o mais acabado paradigma de um processo gradual, é apresentado como se ocorresse bem diante dos olhos do leitor do poema, impressão ainda confirmada pelo uso do verbo no presente do indicativo. Por isso, quando o sentido depois se completa no aposto dividindo em dois o verso seguinte - e desvelando o que vem a ser a tal "coisa fria" que acabara de arredondar o fecho da linha anterior -, é como se fôssemos então submetidos a uma desaceleração inequívoca, cujo efeito tende a tornar ainda mais incisivo o próximo salto. Mas não se pode dizer que se trata de um arranco arbitrário: iniciado com a retomada da conjunção "e" agora no meio do verso, esse movimento desliza com relativa suavidade até o término da frase que o sucede - o que tampouco o livra de produzir novas tensões, resultado nesse caso da nitidez com que, quase ao estilo de um filme em câmera lenta sobre Beatriz Portinari, a frase se concentra em individuar com máxima precisão o atrito entre a respiração do sujeito e o ar em torno. Depois de entrelaçar-se como bruma, a suave resistência desse atrito se verá então objetivada na síntese precária de um "suspiro", imagem que remete agora muito menos à evanescência do que a uma concretização momentânea, e gera assim uma reversão, ironia das ironias, que não por acaso inverte radicalmente o sentido que costuma se associar a tal signo. Aliás, considerando-se ainda o sem número de vezes como, no Drummond dos Novos poemas (1948) em diante, os processos tendem a sempre terminar em sublimação ou evaporação - traço comprovado pela alta incidência dos verbos "dissolver" e "diluir" em muitos desses livros -, é inquietante perceber como, num texto que já foi tomado por muitos como o epítome da evanescência e da perda do contato com o mundo, o trajeto se dirija de forma tão convicta na direção oposta - em que pese a não pouca dificuldade criada pelo serpentear da frase como um todo, de que é também 
exemplo o modo como, logo de início, ela não se furta a elidir sujeito e objeto na contraposição aparentemente inespecífica do "frio ao frio".

Que o excesso de concentração dessa abertura precise ser depois atenuado por uma nova tomada de fôlego é uma exigência claramente confirmada na estrofe seguinte, quando o termo despistado em elipse nos versos 3 e 4 se vê de novo explicitado em 2 verbos reflexivos na primeira pessoa do singular. Com um andamento muito mais distendido do que a estrofe anterior, a soma de ações no presente, nesse caso, é quase como uma rima semântica indireta com o fecho da estrofe, que, ao anular em conclusão deceptiva o suspense das últimas linhas, ganha assim em retrospecto a aparência de um ritmo mais ou menos previsível, não obstante o efeito de leveza criado pelos enjambements. Assim, quando o movimento se vê de novo estancado em outro verso seco, é como se, nesse elo de necessária implicação recíproca entre os dois tempos verbais - quais sejam, entre uma continuidade apenas tenuemente demarcada de um processo interno ("sentia") e novo afastamento gerado quando, na sequência, o passado perfeito põe um termo impreciso mas inexorável à indeterminação ("e lá se foi secreto, ao serro frio") - nos fosse dado assistir à cristalização de um padrão rítmico oscilante, convertido quase em passatempo engenhoso na dupla de estrofes seguintes. Começando ambas com uma asserção em stacatto, elas se verão dinamicamente reequilibradas pelo movimento adversativo do raciocínio, primeiro sob a forma de disjunção ("Perdi minha alma à flor do dia, ou já perdera / bem antes sua vaga predaria?”), e depois na antecipação-hipótese de um caminho que livrasse o sujeito da repetição eterna ("De tantas perdas uma clara via / por certo se abriria"). Com a pequena mas necessária ressalva de que, como deixa claro o complemento do verbo transitivo na linha seguinte ("de mim a mim, estela fria"), o que parece estar em questão agora tem muito menos a ver com o traçado de um percurso que dê forma à corrosão dos dias do que com a intransponível distância do eu em relação a si mesmo. Entre um instante e outro, contudo, na flutuação dos nexos regenciais de alguns processos, a sensação de fluxo desimpedido que a cifra rítmica induz se vê aqui e ali interceptada por pequenas violências em filigrana, dentre as quais a mais impressionante de todas, talvez, seja aquela que corresponde à conversão do verbo "nascer" em reflexivo na pergunta retórica final da terceira estrofe ("e me nasci votado à perda / de frutos que não tenho nem colhia?”). Tomada certa distância, porém, é verdade que tais choques tendem a quase passar despercebidos em meio ao jogo de báscula entre assertiva e contemporização, efeito intensificado ainda pela forma bem mais simétrica da terceira e quarta estrofes, respectivamente com 6 e 8 versos. Coincidência ou 
não, se a linha destacada como uma frase completa no meio de uma delas ("As árvores lá fora se meditam") sugere de novo um contágio-quiasmo entre interior e exterior, cuja eloquência decorre exatamente da desconexão que destaca a frase em relação ao entorno, não é menos verdade que, para um leitor que já tenha em mira a abrupta mudança de ângulo na estrofe seguinte, ("Ah, chega de lamento e versos ditos"), não seria difícil pensá-las como dois segmentos de um bloco único, cuja serenidade só fará sublinhar o impacto da linha iniciada pela interjeição. Num corte que se perfaz como uma modulação repentina face ao andamento bem mais distanciado dos outros 24 versos - devidamente protegidos pela ancoragem das orações principais em passados perfeitos - é quase como se, da interjeição em diante, o que parecia até ali uma narrativa à distância adquirisse com isso a vivacidade de um gesto dramático paradoxal, capaz de funcionar tanto como intensificação quanto como parábase, tanto como um voto performativo quanto um afastamento momentâneo de uma hipnose sonora.

De certo modo, na súbita passagem de marcha aí acionada, o rasgo que essa lamentação imprime no tom meditativo não deixa de lembrar um pouco a soma de perfis cubista do famigerado "Poema de sete faces" de Alguma poesia (1930), um eco que pode ser ainda confirmado pela nova mudança de tom marcando a metade final do nosso poema, desdobrado numa sequência de apóstrofes a entidades como o "Dia", "Deus" e a "Terra", todas convenientemente destacadas por iniciais maiúsculas. Diga-se de saída, porém, que reconhecer aqui a persistência desse fio condutor - cujo espectro inclui um multiforme jogo de endereçamentos e angulações entre sujeito e mundo, entre poesia do coração e prosa da vida -, não significa perder de vista a diferença não menos brutal entre as duas peças: se no caso desse que é o prólogo-moldura da obra de Drummond, estamos em face de um todo metódica e retorcidamente escarpado e que progride aos arrancos, os ritmos encantatórios que predominam em "Elegia" caminham sobretudo no sentido de atenuar as transições entre os diversos estados afetivos, aqui desdobrados num registro muito mais uniforme e sem arestas - a inegável distância, portanto, do chamado "estilo mesclado" do primeiro Drummond. Mal comparando, enquanto em muitos dos poemas escritos ao longo das décadas de 30 e 40 é como se o leitor jamais pudesse ter certeza do que irá aguardá-lo no próximo verso, no caso específico de "Elegia", a delicadeza com que temas e palavras migram de uma linha a outra, como num revezamento, resulta antes num tênue equilíbrio de continuidade e surpresa, que parece também forçar a leitura a retroagir em busca de um movimento de preparação menos ostensivo, mas nem por isso menos presente. É o que parece 
se dar, por exemplo, quando o tríptico de apóstrofes já mencionado deixa-se entrever como retomada e amplificação de um gesto esboçado em plano menor algumas linhas antes; mais especificamente quando a interjeição que é também diálogo do sujeito consigo próprio - ao mesmo tempo em que prepara o bater em retirada da quinta estrofe ("E vou me recolher/ ao cofre de fantasmas") - precisará se haver com o atrito gerado pela anáfora do "ouvido"; tropo que serve de apoio tanto para essa típica coisa interceptante que é o muro quanto para uma piscina aí prosaicamente liberta de qualquer atributo antropomórfico explícito. E que por isso mesmo, é quase como o duplo de uma testemunha inteiramente alheada a um drama interior. Numa tocada que parece também reiterativa demais para ser somente fortuita, um movimento sob muitos aspectos comparável a esse jogo de ecos irá atravessar ainda as 3 estrofes-apóstrofes, que, apesar da solenidade dos vocativos iniciais, tem alguma coisa de palavra-puxa-palavra no modo como progridem. Apenas para citar um caso óbvio, é um traço facilmente constatado quando, reiterando o efeito de amplificação criado a partir de muro e piscina, um sintagma como "Meu Deus, essência estranha/ do vaso que me sinto, ou forma vã", ecoa a metonímia dos "oratórios já vazios" e da "promessa dos deuses" da estrofe 7 , processo retomado ainda quase na mesma proporção no salto seguinte, quando, em outro belo exemplo de despiste, a "Terra" se insinua como uma refração semântica da planície que é o eixo do longo sintagma desdobrado ao fim da segunda interpelação. A estar correto esse raciocínio, portanto, pode-se também entender porquê, no extremo oposto do poema, a última estrofe repita em clave diferida o recuo já esboçado no voto de recolher-se ao "cofre de fantasmas" - no mesmo gesto que sela o início de uma perturbadora contradição performativa. Ou isso, pelo menos, é o que dá a impressão de ocorrer quando, entre a terceira e a penúltima linha dessa mesma estrofe, depois de parecer querer colocar-se em definitivo "longe do amor desabitado e líquido", a voz servindo de prumo à oscilação passa então a monumentalizar via reiteração nervosa o mesmo termo de que há pouco se declarara emancipada, até convertê-lo no indiscutível protagonista do trajeto que é como um fecho de abóbada para o poema. A principio, ainda que essa repetição não deixe de lembrar um pouco uma operação de exorcismo, é preciso reconhecer que, mesmo sem a letra maiúscula das outras prosopopéias, o termo que dá apoio à longa invocação ganha assim um relevo similar ao dos 3 nomes interpelados pela voz lírica, antes da solene despedida final. Por outro lado, ao adotar claramente o registro da hipérbole - de que pode ser exemplo a multiplicação a um só tempo mítica e metódica do algarismo 7, emprestando à vivência contabilizada 
aura de maldição arquetípica -, esse termo não deixa de tornar ainda mais contundente a conclusão do poema, quando numa mistura de captatio benevolentiae e coquetismo ("E já não sei se é jogo, ou se poesia"), tudo parece de chofre amenizado pelo retorno da rima. O mais curioso, entretanto, é que, sob essa aparente superfície de serenidade, o mesmo gesto que interrompe e relativiza a prosopopéia do amor encerra também a elevação da voz lírica acima de si mesma; motivo cujo momento mais alto, talvez, seja o tropo do "desmonte palmo a palmo" na estrofe 5, no qual pode-se entrever ainda um aceno indireto à pseudo-chave de ouro do último verso.

Numa primeira recapitulação, portanto, isso que pode soar tão confortável e eufônico se visto de fora - quando parece ter a mesma leveza de um dar de ombros - não deixa de implicar também uma reivindicação de controle enviesada, que equivaleria à nêmese da instância crítica que se precisou antes negligenciar para que o poema subisse de tom. Note-se ainda que, se é o caso de converter essa reviravolta final em traço intransferível, ela só faria endossar o pendor da dicção drummondiana para o anti-clímax e o embate com o vazio, podendo nos remeter a títulos como "O procurador do amor" e "Cantiga de viúvo", cujo acento entre amargo e humorístico, como se sabe, não decorre senão do esmero como o fiasco da última linha é meticulosamente preparado pelas que a antecedem. Deslocada, no entanto, a ênfase do repto de auto-crítica para a das múltiplas ressonâncias acionadas com a evocação do jogo - termo que não por acaso já vinha insinuando na insistente rede de contrapontos que uma leitura atenta desenha -, interessante perceber também como a síncope em negaceio do desfecho parece convidar o leitor a reler todo o trajeto nos termos de um contrabalançar de correspondências mais ou menos oblíquas, de que o melhor exemplo, talvez, sejam as 13 vezes que a palavra "frio" se repete ao longo do poema, truque que desempenha sem dúvida papel crucial no transe hipnótico do conjunto. Isso para não mencionar também a própria disposição dos versos, que, mesmo evitando abertamente a regularidade, passa longe das assimetrias muito mais salientes de um típico poema modernista. Com efeito, seja pela desenvoltura como alternam hipotaxe e parataxe, seja pelo suspense criado por reversões que obstruem a fluência de alguns enjambements - os quais, diga-se de passagem, podem tanto alargar até o infinito o escopo de um termo quanto reduzir o mundo a mera reverberação da tautologia do eu -, essa lucidez em relação aos próprios meios, evidente no zelo com que o poeta apaga as pegadas que garantem a ordem do texto, poderia até se aproximar por vezes de um encalacramento esteticista, não fosse o tato como, nesse perde-ganha de refrações semânticas, o 
poema elege por matéria-prima essas verdadeiras moedas sem efígie que são as catacreses - quase como se repetisse em escala reduzida o próprio desgaste do tempo. De um modo geral, entretanto, não há dúvida de que a sutileza extrema de tais recursos parece aqui não raro perder terreno para a sensação de uma ininterrupta troca de qualidades entre sujeito e objeto, que se dá agora ao ônus de uma (deliberada) perda de especificidade de cada enunciado, agravada não apenas pelo uso repetido do artigo definido como ainda pela eliminação daquelas pequenas metonímias incisivas que davam tanto gume ao primeiro Drummond. Isso dito, se há ainda assim um vetor lutando para conter tal evanescência, ela passa de certo pelo destaque conferido, nos versos finais, a esse estranho acidente-em-substância popularmente conhecido como "amor", nesse poema alçado claramente à posição de antagonista. Via de regra, é verdade que depois da breve intromissão hitchcockiana na quinta estrofe ("os olhos policiais do amor-vigia"), a sua suposta volta triunfal ao fim do poema mantém-se à salvo de qualquer rosto identificável que lhe dê lastro, funcionando em última instância, portanto, muito menos como elo de ligação entre o eu e o presumido alvo de sua super-estima do que como uma entidade que castiga sem complacência um pronome oblíquo ("amor em que me amaram, me feriram/sete vezes por dia, e sete dias/ de sete vidas de ouro"). Cifra de todos os assaltos a que o mundo verga o sujeito, esse penar tem como condição de possibilidade, ao que parece, o glissando pelo qual, quase em surdina, um afeto que imaginava-se como tendo sede e origem no próprio indivíduo é convertido na ficção de uma entidade exterior que passa a comandá-lo de fora, até desvelarse moto perpétuo de uma decepção sem saída ("amor, fonte de eterno frio"). De sorte que, na medida em que abre uma zona de passagem difusa entre sujeito e objeto, o mais suave que se pode dizer dessa torção é que ela tem implicações incalculáveis para o entendimento do poema como um todo. Mais que isso: se tomado como uma chave capaz de elucidar o funcionamento do texto, essa conversão de um estado mental em figura antropomórfica - não bastasse trair ainda toda a intimidade de Drummond com a tradição da lírica do Ocidente, de Vita nuova em diante - soa como a síntese dramática de uma contraposição mais fundamental, senha da estranha relação ativa-passiva do eu com o próprio ir e vir da linguagem na qual este se deixa levar e/ou afogar. Em mais de um sentido, é um processo extensível também até o status dos clichês de perda e ganho já aqui destacados, prolongando-se ainda na maneira como, ao apresentar esses clichês como um tipo de chassi vazio à espera de eventos e fatos que o estabilizem, o poema inverte drasticamente uma ordem de prioridade que se supõe como certa, sempre que se 
trata de dispor sujeito e linguagem nos termos de um nexo unidirecional de causa e efeito. Nunca será demais ressaltar, no entanto, que é justo por recusar soluções de compromisso como essa - no mesmo gesto que expõe a funcionamento letal das mais inofensivas catacreses - que "Elegia" parece resistir com tanta tenacidade às referencializações ingênuas; o que, salvo engano, é o que ocorre sempre que se trata de tentar ligá-lo a uma suposta realidade exterior, de que seus tropos estariam por assim dizer a serviço. Não sem motivo, isso reverbera ainda na insistência como - uma vez colocadas em parêntese tais sutilezas - o conflito cerrado que aí se desdobra se vê reiteradamente deslido como perda de concretude, líquida evanescência, compasso de espera, crise do projeto etc.

Embora essa questão seja quase imperceptivelmente esvaziada pela textura do poema, é preciso reconhecer que, para voltarmos mais uma vez às catacreses contábeis, a configuração que adquirem na "Elegia" tem um viés muito distinto daquele de outros poemas de auto-exame que fazem uso delas, como é o caso de "A flor e a náusea", "Os ombros suportam o mundo" e "Não se mate", todos eles situados antes da mencionada inflexão classicista. De fato, se na maior parte da produção do Drummond dos anos 30 e 40, o emprego dessas metáforas de guarda-livros tende a converter em inventário atonal o amontoado de choques e resistências de que é feito o mundo, em "Elegia", ao contrário, essa disposição a confrontar tudo com tudo se desloca para um plano bem menos tangível de monogramas ocultos - incidindo o rasgo de dissonância agora muito menos via contraposição em zeugma de dois termos claramente discrepantes ("preso à minha classe e a algumas roupas") do que graças ao ligeiro efeito desfigurador de certos deslocamentos. Se pensarmos ainda em como isso se deixa fenomenalizar em termos de estrato fônico, a escolha ajuda também a entender a diferença, por exemplo, entre a impressão mercurial gerada por essa "Elegia" e a linguagem de força que toma de assalto o fecho de muitos desses acertos de contas, num arco envolvendo desde os imperativos que selam o apaziguamento de "Não se mate" ("mas não diga nada a ninguém/ninguém sabe, nem saberá") até o célebre "Há que amar e calar", de "Campo de flores"; verso no qual, pode-se supor, a intensificação induzida pela palavra de ordem se soma ao reconhecimento da impossibilidade de se transmitir a quem quer que seja aquilo que se viveu. Na medida em que se fazem portanto também acompanhar de uma decidida renúncia à porosidade - em ambos também fiador da autoridade da vOz remoendo dentro de si a crispação do presente -, é como se o ganho de lucidez de tais desfechos decorresse sempre da capacidade de conservar e negar num único arranjo todas a desconexões e asperezas do curso 
do mundo. Longe de se encerrar nesse tom de desengano, contudo, talvez seja exatamente por colocarem em xeque a esperança de contato que esses poemas têm a capacidade de funcionar como uma interpelação combativa para quem os lê, efeito de certa maneira já previsto na convenção da voz se dirigindo a si mesma como se fosse um outro. Ao garantir assim uma inviolável reserva de distância ao sujeito retorcido - cuja imensa força de convencimento junto ao seu leitor não decorre senão da capacidade de formalizar e expor uma experiência assintótica , o que se vê então é antes um movimento no qual o reconhecimento da indiferença do mundo em relação a desejos e valores nem por isso chega a alijá-los de sua substancialidade. Ao contrário: expondo-os quase como um resto que sobra depois que todo o passivo é contabilizado em um dos lados da folha, em seu convite ao ceticismo e à auto-ruminação, essa somatória desapiedada das próprias perdas resulta, num poema como "Não se mate", por exemplo, na construção de um enclave onde o sujeito se abriga por um instante da cacofonia do mundo, sem no entanto jamais perder o poder de discernir cada um dos ruídos e estridências que a compõem. Consequentemente, ao ligarem a força de cada mergulho introspectivo à capacidade de reconhecer, cercar e nomear a negatividade enquanto tal - o que significa também cavar um golfo intransponível entre mundo e sujeito -, difícil pensar em maior afastamento do que parece ser, para muitos, o sentido dominante de "Elegia", onde o que se tem, de acordo com a leitura hegemônica, é antes um dissolvente jogo de ecos entre dentro e fora, em meio ao qual já não há mais nada parecido com a Ilha de Manhattan para fazer as vezes de inimigo. Se isso pode a princípio soar quase como uma variante versificada de uma indiferenciação sem foco, um relato que tentasse organizar em linha diacrônica a diferença em questão, na passagem da linguagem de força até à "ingaia ciência", poderia sugerir que estaríamos então diante de algo próximo de uma capitulação indolente; um pouco como se, depois de resistir até onde era possível na sua intransitividade, essa voz finalmente se contentasse em despistar em eufonia uma inelutável erosão temporal, enquanto a vida ia aos poucos se reduzindo a uma grande máquina termodinâmica de esfriar entusiasmos. A rigor, pensando em como esse impasse será depois digerido em termos de fortuna crítica, ele pode tanto colocar em xeque a validade da obra como um todo - como é o caso dos que acusam o Drummond dessa fase de ter

perdido "os fios do concreto e do projeto" (Décio Pignatari) ${ }^{2}$ - quanto dar lugar a leituras que tentem decifrar as entrelinhas do socius nessa opacidade intransponível,

2. PIGNATARI. Contra-comunicação. 
como é o que se viu no livro de Vagner Camilo, ${ }^{3}$ onde o imbróglio é habilmente resolvido em clave adorniana. Ressalve-se porém que, se há um ônus que surge como praticamente inevitável em abordagens como essa - que, até onde consigo ver pelo menos, pressupõem por assim dizer a necessidade de mediar e traduzir o mundo exterior no sumário da forma, cuja força é indissociável de uma consciente e deliberada recusa à compreensão fluida -, este diz respeito sobretudo ao movimento irresistivelmente centrífugo que o raciocínio impõe sobre a lida com o texto, um texto que, justo por ser capaz de filtrar e refratar toda e qualquer coisa, parece resolutamente infenso à saturação, abrindo-se com isso num espectro onde, para dar conta do modo como cada poema se transforma na "antítese social da sociedade", pode-se incluir desde o cotejo com algumas considerações sibilinas de Passeios na ilha até o malfadado envolvimento do poeta com os comunistas; desde uma sondagem de campo literário à Bordieu até um discussão sobre a retomada polêmica do diálogo com a tradição de Sá de Miranda, Camões e outros. Tudo contado, mesmo que não esteja em dúvida a pertinência de tais digressões - ainda mais face a uma dicção tão alusiva como a de Drummond -, não deixa de ser intrigante notar como uma simples (re) leitura cerrada dos 4 primeiros versos de "Elegia" parece por si só suficiente para tornar ocioso esse tipo de apelo, ao nos colocar diante de um artefato onde a crispada experiência social da Modernidade se cristaliza menos numa alusão subreptícia a ser decifrada do que no extremo rigor com que categorias lingüísticas se contra-balançam e se agridem umas às outras:

Ganhei (perdi) meu dia

e baixa a coisa fria

também chamada noite, e o frio ao frio

em bruma se entrelaça, num suspiro.

Diante da condensação virtuosística do verso 4 - à qual espero ter dado o devido destaque na primeira tentativa de aproximação, páginas atrás -, é provável que a parataxe do primeiro dístico tenda a soar um pouco facilitadora no modo como atenua em rima coisas tão diversas. E ainda assim, supondo-se que já estejamos devidamente calejados pelo que virá na sequência - como é o caso da falta de mediação, por exemplo, entre a síntese violenta de um verso como "Gastei meu dia. Nele me perdi” e o entorno hipotático que pode até parecer amortecêlo, mas não explicá-lo -, um elemento que logo salta aos olhos, na leitura retroativa,

3. CAMILO. Drummond: da rosa do povo à rosa das trevas. 
é a ausência de qualquer hierarquia mais explícita entre os dois eventos enlaçados via conjunção paratática. Tensão que pode muito bem ser resolvida da forma prosaica - supondo-se que trata-se apenas de mais um arroubo melancólico de final do dia -, é bem verdade que um olhar um pouco mais detido sobre tais versos nos leva a hipóteses capazes de quebrar um pouco essa impressão de clareza, dentre as quais a mais provocadora de todas, talvez - ou pelo menos, a que mais resistência colocaria sobre o fluir da leitura -, seria ver na síntese assertiva da primeira linha o abrigo ou mecanismo de defesa de um sujeito contra o processo de duração indefinida que corresponde ao cair da noite, momento que é por si só um ótimo correlato sensível da indefinição semântica extrema. Nesses termos, se traço indissociável ao fim do dia é exatamente a dificuldade de definir de uma vez por todas o ponto em que este se dá, tampouco parece arbitrário que a resposta do sujeito diante disso caminhe exatamente no sentido de uma possível equivalência final entre os extremos de um código binário, instrumento ainda assim estranhamente desajeitado face a uma progressão claramente infensa a contornos fixos. Lida, no entanto, como a transição inexorável que também não deixa de ser - espécie de soleira móvel "entre lobo e cão", entre lucidez e cegueira -, curioso perceber como o ponto final do processo, que poderia corresponder no poema ao embate com o apelido mais conhecido da tal "coisa fria", parece por isso mesmo desde já condenado a se desatar em burla sutil, cuja infalibilidade não resulta senão da impotência do medidor subjetivo para marcar o ponto que sela e totaliza a morte do dia. Para não falar na inigualável radicalidade com que, a partir de um pequeno arsenal de metáforas que perderam o gume, a experiência se mostra assim como um casamento infinitamente adiado entre linguagem e mundo, embate aí tornado evidente, por exemplo, na supressão literalmente incalculável que tais metáforas provocam sempre que tentam traduzir o sentido do dia em narrativas de progressão ou regressão.

Estendendo-se como um leitmotiv obsessivo na obra de Drummond, essa luta renhida entre mundo e consciência - dispositivo que, justo por saber "o preço exato/dos amores, dos ócios, dos quebrantos”, sabe também o que há inútil e desesperado em tal mensuração ("amor, quem contaria?") -, reverbera ainda no pendor que tem essa poesia pela reticência e pelas meias tintas, e a leva a despistar com tanto virtuosismo seus dispositivos centrais. Não por acaso, como bem observou Hélcio Martins, 'é um traço que guarda muito mais que uma vaga semelhança com

4. MARTINS. A rima na poesia de Carlos Drummond de Andrade. 
a ação corrosiva do tempo, de que estratégias como a detectada na estrofe de abertura - operando na breve contraposição do pretérito imperfeito ao sfumato da ação no presente - seriam por assim dizer um duplo mitigado. E ato contínuo também, a maior e mais discreta façanha do poema inteiro - todo ele construído como um grave exercício lutuoso por tudo aquilo que parece resistir à objetivação, chame-se isso "Dia", "Deus" ou "amor". Em última análise, portanto, ao concretizar esse movimento furtivo num pequeno atraso ou recuo - tendo lugar na defasagem entre a noite que chega e o esforço de auto-exame -, é como se ela realizasse sem alarde uma insólita ainda que total identificação com o seu maior inimigo, correspondendo o seu desdobramento, de linha a linha, à reiterada tentativa de pacificar num jogo de báscula uma irrupção que não cessa de não se fixar nos mais variados suportes, e diante da qual o sujeito é sempre devolvido à condição de oratório vazio, recipiente oco, ou "estela fria". No mínimo, é um retorno que se faz quase inevitável quando, tão logo se começa a adquirir certa intimidade com as regras do jogo - aqui exposto como um intrincado sistema de compensações entre desfiguração semântica e hipnose sonora, onde uma das mãos parece estar sempre derrubando aquilo que a outra constrói -, o que passa a estar em primeiro plano, em suma, é muito menos o peso e a validade daquilo que se quer medir do que a distorção estrutural inerente ao próprio instrumento de medição; impasse que repercute sem dúvida no modo como "Elegia" expõe os mecanismos pelos quais se tenta dar forma e sentido ao tempo, num arco que cobre desde uma arquitetura quase invisível de rimas despistadas até a lenta calcificação de metáforas em pequenas frases feitas de final de expediente, ditas para pôr termo a um ciclo que quase parece eterno tal a regularidade com que se repete. Não tivesse Drummond o tato e sentido que tem para sua hora histórica - capturada, como se vê, muito menos em forma de remissão direta a fatos específicos do que na ênfase sobre os dispositivos que são desses fatos a condição de possibilidade, e sem os quais lhes é impossível assumir tamanho e contorno - e o impasse gerado pela tarefa talvez se transformasse em apenas mais uma variante corrosiva da tópica da efemeridade, o que poderia ser até uma sutura reconfortante face aos abismos sucessivamente abertos de um verso a outro. No corpo do poema como um todo, porém, tentar resolver os problemas nessa clave - como se tudo não passasse de um jogo ocioso, ou de regressão neoclássica - seria ignorar o autocontrole implacável com que, tendo por eixo algumas das metáforas mais surradas pelas quais vivemos, como "ganhar", "perder", "gastar" e "contar", o seu desenho explicita e cristaliza toda a pobreza e negatividade da experiência moderna, aqui traduzida num 
dispositivo onde a soma de perdas implicadas em cada esforço de síntese toma precisamente por foco o intervalo entre, de um lado, certa proliferação maníaca de formas de medida - colonizando até as mais ínfimas capilaridades da linguagem rotinizada - e a aparente indistinção de tudo isso num único e prolongado embotamento. Até finalmente se decantar em inscrição na qual, despistada pelo labor da eufonia e dos ritmos sinuosos, a violência surda dos dias que passam adquire a mesma falsa serenidade de um registro num livro de partidas dobradas.

The world in double entry (a reading of Carlos Drummond de Andrade's "Elegia”)

Abstract: A reading of Carlos Drummond de Andrade's "Elegia", this essay focuses on the rhetorical and political implications of its form, taking as a point of departure the tensions between poetry and the crisis of experience in modern world.

Keywords: form, experience, rhetoric.

$$
\text { Referências }
$$

BENJAMIN, Walter. Obras escolhidas I. São Paulo: Brasiliense, 1990.

CAMILO, Vagner. Drummond: da rosa do povo à rosa das trevas. Cotia: Ateliê editorial, 2001.

CAMPOS, Haroldo de. Metalinguagem e outras metas. São Paulo: Perspectiva, 1992. CANDIDO, Antonio. Vários escritos. São Paulo: Duas cidades, 1995.

COSTA LIMA, Luiz. Lira e antilira. Rio de Janeiro: Topbooks, 1995.

DE MAN, Paul. The rhetoric of romanticism. New York: Columbia University Press, 1995.

DRUMmOND DE ANDRADE, Carlos. Poesia e prosa. Rio de Janeiro: Nova Aguilar, 1992.

MARTINS, Hélcio. A rima na poesia de Carlos Drummond de Andrade. Rio de Janeiro: Topbooks, 2005.

MERQUIOR, José Guilherme. Verso Universo em Drummond. Rio de Janeiro: José Olympio, 1975.

PIGNATARI, Décio. Contra-comunicação. São Paulo: Perspectiva, 1971. 